\title{
A new method to measure Bowen ratios using high-resolution vertical dry and wet bulb temperature profiles
}

\author{
T. Euser ${ }^{1}$, W. M. J. Luxemburg ${ }^{1}$, C. S. Everson ${ }^{2}$, M. G. Mengistu ${ }^{2}$, A. D. Clulow $^{2}$, and W. G. M. Bastiaanssen ${ }^{1}$ \\ ${ }^{1}$ Delft University of Technology, Water Resources Section, Stevinweg 1, 2628 CN Delft, the Netherlands \\ ${ }^{2}$ Centre for Water Resources Research, School of Agriculture Earth and Environmental Sciences, University of \\ KwaZulu-Natal, Private Bag X01, Scottsville, 3209 Pietermaritzburg, South Africa \\ Correspondence to: T. Euser (t.euser@tudelft.nl)
}

Received: 2 May 2013 - Published in Hydrol. Earth Syst. Sci. Discuss.: 5 June 2013

Revised: 27 March 2014 - Accepted: 12 April 2014 - Published: 3 June 2014

\begin{abstract}
The Bowen ratio surface energy balance method is a relatively simple method to determine the latent heat flux and the actual land surface evaporation. The Bowen ratio method is based on the measurement of air temperature and vapour pressure gradients. If these measurements are performed at only two heights, correctness of data becomes critical. In this paper we present the concept of a new measurement method to estimate the Bowen ratio based on vertical dry and wet bulb temperature profiles with high spatial resolution. A short field experiment with distributed temperature sensing (DTS) in a fibre optic cable with 13 measurement points in the vertical was undertaken. A dry and a wetted section of a fibre optic cable were suspended on a $6 \mathrm{~m}$ high tower installed over a sugar beet trial plot near Pietermaritzburg (South Africa). Using the DTS cable as a psychrometer, a near continuous observation of vapour pressure and air temperature at $0.20 \mathrm{~m}$ intervals was established. These data allowed the computation of the Bowen ratio with a high spatial and temporal precision. The daytime latent and sensible heat fluxes were estimated by combining the Bowen ratio values from the DTS-based system with independent measurements of net radiation and soil heat flux. The sensible heat flux, which is the relevant term to evaluate, derived from the DTS-based Bowen ratio (BR-DTS) was compared with that derived from co-located eddy covariance $\left(R^{2}=0.91\right)$, surface layer scintillometer $\left(R^{2}=0.81\right)$ and surface renewal $\left(R^{2}=0.86\right)$ systems. By using multiple measurement points instead of two, more confidence in the derived Bowen ratio values is obtained.
\end{abstract}

\section{Introduction}

Evaporation is - after rainfall - the most important term of the hydrological water balance (Gleick, 1993). Evaporation is also a major term of the land surface energy balance, i.e. the latent heat flux. Knowledge on the consumptive use of water is key for water scarce areas, where consumptive use mainly consists of evaporation (Perry, 2007). An accurate estimation of the actual evaporation can be used for hydrological studies, environmental studies, irrigation studies, climate change studies, water accounting studies and solving international conflicts on the verification of water use. It is often difficult and costly to estimate the actual evaporation above land surfaces accurately. Therefore, actual evaporation is often estimated using numerical simulations of hydrological processes (e.g. Schoups et al., 2008; Uhlenbrook et al., 2004), soil-vegetation-atmosphere-transfer processes (e.g. Sellers et al., 1986; Wipfler et al., 2011) and remote sensing algorithms (e.g. Bastiaanssen et al., 2012; Courault et al., 2005; Kalma et al., 2008). Models, however, often require ground measurements for calibration (Xing et al., 2008).

Conventional techniques for ground measurements of evaporation differ in aspects such as complexity, applicability, accuracy and costs. Review papers on lysimeters, soil water balances, the Bowen ratio method, eddy co-variance systems, scintillometers and surface renewal techniques are provided by Burt et al. (2005), Dugas et al. (1991), Malek and Bingham (1993), Mauder et al. (2013), Rana and Katerjib (2000) and Teixeira and Bastiaanssen (2011). We provide a new method that one can select when contemplating all these aspects. In addition, this method provides high-resolution 
information about temperature and vapour pressure profiles in the air.

The conventional Bowen ratio surface energy balance method (BR method) is a relatively simple technique that integrates net available energy with the ratio of the sensible and latent heat flux. The Bowen ratio can be determined by multiplying the psychrometric constant by the ratio of the temperature and vapour pressure gradients (Bowen, 1926). Combining the Bowen ratio with net radiation $\left(R_{\mathrm{n}}\right)$ and soil heat flux $(G)$ makes it possible to determine the latent heat flux. Many studies have investigated the use of the BR method to estimate the sensible and latent heat fluxes (Aston, 1985; Black and McNaughton, 1971; Jara et al., 1998; Peacock and Hess, 2004; Savage et al., 2009; Teixeira et al., 2007). The BR method is usually derived from two-level air temperature and water vapour pressure sensors. A drawback of this is that the two sensors need to accurately agree with each other, in order to observe small differences of temperature and vapour pressure at two heights (Angus and Watts, 1984; Fritschen and Qian, 1990; Fuchs and Tanner, 1970). Some suppliers of the equipment overcome this issue by mechanically alternating the position of the sensors.

This paper presents an alternative method that overcomes the need to install separate sensors. This method, referred to as the BR-DTS method, determines the temperature and vapour pressure gradients using a distributed temperature sensing (DTS) method. With the DTS technique (Selker et al., 2006; Tyler et al., 2009) temperature measurements with a high temporal and spatial resolution are obtained using one sensor, a fibre optic cable. Vertical high-resolution air temperature and vapour pressure profiles are obtained with sampling resolution of $0.2 \mathrm{~m}$ across a total height of $4.5 \mathrm{~m}$. This eliminates the major shortcoming of the conventional BR method with separate sensors on two levels. By having the vertical gradients from multiple levels obtained with the same sensor, it is expected that the Bowen ratio can be determined with more confidence than for the situation where separate sensors on two levels are used.

The price of laser analysing equipment has decreased rapidly over the last few years and we expect to see a reduction in the cost of DTS equipment in the near future as well. This reduced cost together with the improved sampling resolution of up to $0.2 \mathrm{~m}$ demonstrates the developments and interest in the technique. The DTS technique is increasingly applied in different research fields, thus, showing the potential of the technique (Blume et al., 2013; Krzeminska et al., 2011; Steele-Dunne et al., 2010; Westhoff et al., 2010; Hoes et al., 2009).

The aim of this study is to test the usefulness of the BRDTS method with respect to reference techniques and the conventional BR method. An effective measurement period of 5 days has been selected to undertake a first investigation. The results are compared with conventional in situ measurement techniques. The advantages and disadvantages of this new BR-DTS technique are discussed.
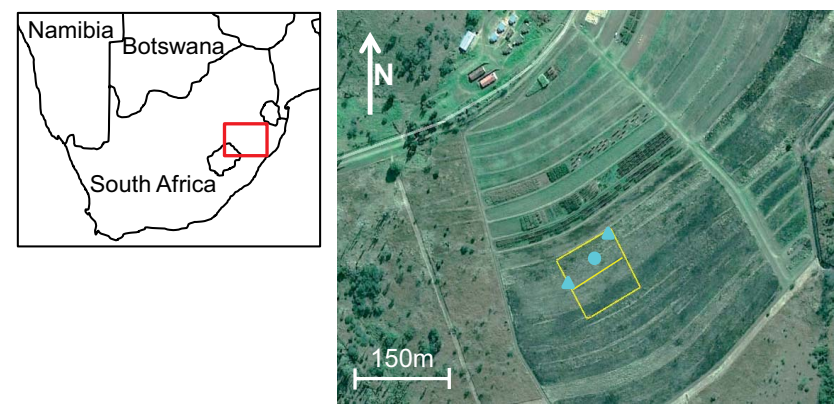

Figure 1. Location of the Ukulinga research farm. The blue dot indicates the location of the experimental setup for the BR-DTS, eddy covariance and surface renewal measurement systems. The blue triangles indicate the position of the transmitter and receiver of the surface layer scintillometer.

\section{Materials and methods}

\subsection{Study area}

The field measurements were carried out on a sugar beet field located at the Ukulinga research farm of the University of KwaZulu-Natal, Pietermaritzburg (South Africa). The field is located at $29^{\circ} 40^{\prime} 22^{\prime \prime} \mathrm{S}$, and $30^{\circ} 24^{\prime} 25^{\prime \prime} \mathrm{E}$ and the land has a gentle slope $(<5 \%)$ (Fig. 1). The size of the plot is $80 \mathrm{~m} \times 80 \mathrm{~m}$ and the elevation is $780 \mathrm{~m}$ a.m.s.l. (above mean sea level). The crop height of the sugar beet during the experiment was about $0.5 \mathrm{~m}$ and the crops were irrigated with drip irrigation once a week. This site was selected because of an on-going micro-meteorological field experiment of the University of KwaZulu-Natal in the same field.

\subsection{BR-DTS method}

\subsubsection{Theory}

The BR method relies on several assumptions (Angus and Watts, 1984; Fritschen and Simpson, 1989; Gavilán and Berengena, 2007; Spittlehouse and Black, 1980). One basic assumption is that the fluxes are one-dimensional only, with no horizontal gradients, and that measurement sensors are located within the equilibrium sub-layer, where fluxes are constant with height (e.g. Dyer and Hicks, 1970). It is further assumed that the land surface is homogeneous with respect to sources and sinks of heat, water vapour and momentum. The turbulent exchange coefficients for heat and water vapour fluxes are assumed to be equal, resulting in equal surface roughness lengths for heat and water vapour, and identical correction functions for buoyancy (Todd et al., 2000). Under these prevailing conditions, the Bowen ratio can be determined from differences in actual air temperature $\left(\Delta T_{\mathrm{a}}\right)$ and actual vapour pressure $\left(\Delta e_{\mathrm{a}}\right)$ over a vertical air column (Bowen, 1926). The Bowen ratio also describes the ratio between the latent and sensible heat fluxes (Eq. 1). 
$\beta=\frac{H}{\rho \lambda E}=\gamma \frac{\Delta T_{\mathrm{a}}}{\Delta e_{\mathrm{a}}}$,

where $\gamma$ is the psychrometric constant $\left(\mathrm{kPa}^{\circ} \mathrm{C}^{-1}\right), H$ is the sensible heat flux $\left(\mathrm{W} \mathrm{m}^{-2}\right.$ ) and $\rho \lambda E$ is the latent heat flux $\left(\mathrm{W} \mathrm{m}^{-2}\right)$.

The actual vapour pressure can be determined from dry and wet bulb temperature measurements applying the principle of a psychrometer (Allen et al., 1998). The equation for actual vapour pressure is

$e_{\mathrm{a}}=e_{\mathrm{s}}-\gamma\left(T_{\mathrm{a}}-T_{\mathrm{w}}\right)$,

where $T_{\mathrm{a}}$ is the air temperature $\left({ }^{\circ} \mathrm{C}\right), T_{\mathrm{w}}$ is the temperature of a wetted and vented surface (e.g. sphere), often referred to as the wet bulb temperature $\left({ }^{\circ} \mathrm{C}\right), e_{\mathrm{s}}$ the saturated vapour pressure $(\mathrm{kPa})$, and $e_{\mathrm{a}}$ is the actual vapour pressure $(\mathrm{kPa})$. The saturated vapour pressure $e_{\mathrm{S}}$ in Eq. (2) is based on $T_{\mathrm{w}}$ and can be calculated with Eq. (3) (Allen et al., 1998):

$e_{\mathrm{S}}=0.61 e^{\frac{17.3 T_{\mathrm{W}}}{237+T_{\mathrm{W}}}}$.

The psychrometric constant used in Eqs. (1) and (2) depends on the ventilation rate of the psychrometer. In this study, the ventilation rate is determined by the wind speed and cannot be considered constant during the entire experiment. The wind speed dependency is described by Frtischen and Gay (1979) and by Allen et al. (1998). Wind speed was only measured at one height, so only the variability in time was accounted for. Two different values for $\gamma$ have been used: $\gamma=0.059 \mathrm{kPa}^{\circ} \mathrm{C}^{-1}$ for $u>3 \mathrm{~ms}^{-1}$ and $\gamma=0.071 \mathrm{kPa}^{\circ} \mathrm{C}^{-1}$ for $u<3 \mathrm{~ms}^{-1}$. These values are corrected for the elevation of the experimental field (780 m a.m.s.l.).

The combination of Eqs. (1) and (2) and application to a vertical air column with observations at two heights referred to in the subscripts with 1 and 2, after rewriting, yields

$\beta=\gamma \frac{T_{\mathrm{a}, 2}-T_{\mathrm{a}, 1}}{\left(e_{\mathrm{s}, 2}-e_{\mathrm{s}, 1}\right)-\gamma\left(T_{\mathrm{a}, 2}-T_{\mathrm{a}, 1}\right)+\gamma\left(T_{\mathrm{w}, 2}-T_{\mathrm{w}, 1}\right)}$.

Or in general

$\beta=\gamma \frac{\Delta T_{\mathrm{a}}}{\Delta e_{\mathrm{s}}-\gamma \Delta T_{\mathrm{a}}+\gamma \Delta T_{\mathrm{w}}}$.

Equation (5) shows that the difference of air temperature is important for an accurate determination of the Bowen ratio, and that the absolute values are less important. Therefore, the difference between multiple sensors should be accurate. This remark does not hold true for $\Delta e_{\mathrm{s}}$, because the saturation vapour pressure is derived from the wet bulb temperatures (Eq. 5), and the relation between the wet bulb temperature and corresponding saturation vapour pressure (Eq. 3) is non-linear. The consequence of this non-linearity is that, when the wet bulb temperatures at the two measurement levels are equally off, $\Delta T_{\mathrm{w}}$ remains the same, but $\Delta e_{\mathrm{s}}$ can be erroneous.
The Bowen ratio, or $H / \rho \lambda E$ flux, can be combined with measurements for $R_{\mathrm{n}}$ and $G$ in the energy balance equation. From the energy balance equation the latent and sensible heat fluxes (Eqs. 6 and 8, respectively) can be calculated (e.g. Aston, 1985; Fritschen, 1965; Perez et al., 1999). To fully assess the effect of more accurate Bowen ratio values on latent and sensible heat fluxes, the error propagation for these terms is spelled out. The relative error for both the latent and sensible heat fluxes is shown in Eqs. (7) and (9).

$\rho \lambda E=\frac{R_{\mathrm{n}}-G}{1+\beta}$,

$r_{\rho \lambda E}^{2}=\frac{\sigma_{R_{\mathrm{n}}}^{2}+\sigma_{G}^{2}}{\left(R_{\mathrm{n}}-G\right)^{2}}+\frac{\sigma_{\beta}^{2}}{(1+\beta)^{2}}$,

$H=\frac{\beta\left(R_{\mathrm{n}}-G\right)}{1+\beta}$,

$r_{H}^{2}=\frac{\sigma_{R_{\mathrm{n}}}^{2}+\sigma_{G}^{2}}{\left(R_{\mathrm{n}}-G\right)^{2}}+\frac{\sigma_{\beta}^{2}}{(1+\beta)^{2}}+\frac{\sigma_{\beta}^{2}}{\beta^{2}}$,

where $\rho \lambda E$ is the latent heat flux $\left(\mathrm{W} \mathrm{m}^{-2}\right), R_{\mathrm{n}}$ is the net radiation $\left(\mathrm{W} \mathrm{m}^{-2}\right), H$ is the sensible heat flux $\left(\mathrm{W} \mathrm{m}^{-2}\right), G$ is the soil heat flux $\left(\mathrm{W} \mathrm{m}^{-2}\right), r_{i}$ is the relative error of term $i$ and $\sigma_{i}^{2}$ is the variance of term $i$.

\subsubsection{DTS experimental setup}

The temperature distribution along a fibre optic cable is measured with the DTS technique. The DTS measurement device consists of two main elements: (1) a computer equipped with a laser transmitter and receiver and (2) a fibre optic cable. The computer transmits short laser pulses and receives the reflected frequencies. From the amplitude ratios between the reflected frequencies, the temperature can be derived (Selker et al., 2006). From the travel time of laser light in the fibre optic cable, the origin (i.e. position along the cable) of the reflected signal can be deduced. The observed temperature is an average over a cable segment. The segment length, and therefore the sampling resolution, depends on the interval time of the laser pulse.

For this field campaign the ORYX laser pulse of Sensornet was used in single-ended mode, with a sampling resolution of $1 \mathrm{~m}$ along the cable (Sensornet, 2009). For the measurements a data collection time of 5 min was used resulting in a precision higher than $0.05^{\circ} \mathrm{C}$ (Sensornet, 2009). For the sake of comparison with the other flux measurement devices, the data were averaged over $30 \mathrm{~min}$. More background information on the DTS technology can be found in Selker et al. (2006) and Tyler et al. (2009).

The temperature measurements along the cable are subjected to a calibration process (Selker et al., 2006). Both a slope and an offset can occur in the measurements along the cable, both slope and offset can be dependent on temperature. Therefore, a continuous calibration in time was performed: two segments of the cable with a certain distance 

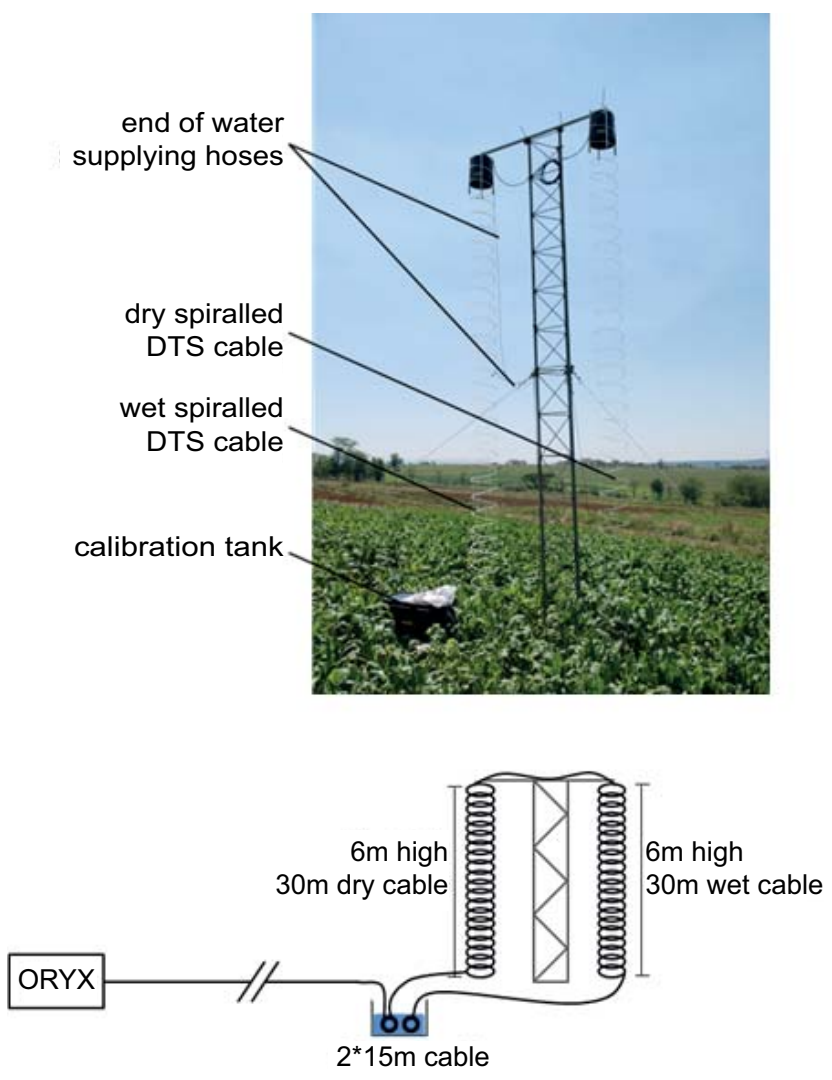

Figure 2. Experimental setup for BR-DTS at the Ukulinga research farm. Top panel: picture of setup in the field. Bottom panel: schematic overview of the setup.

apart were placed in the same water-filled calibration tank for the total duration of the measuring period. The temperature of the water in the tank was measured continuously with four TMC6-HD temperature probes attached to a U-12 data logger (HOBO, onset). The accuracy of the individual temperature measurements was $\pm 0.25^{\circ} \mathrm{C}$, with a precision of $0.03^{\circ} \mathrm{C}$. The temperature of the water showed diurnal variations around $20^{\circ} \mathrm{C}$; slope and offset coefficients for the calibration were determined every $5 \mathrm{~min}$.

The BR-DTS system (Fig. 2) was installed on a lattice mast situated so that the longest fetch over the sugar beet corresponded to the dominant wind direction, which was from the south-west. By wind from the south-west, the fetch runs over $80 \mathrm{~m}$ of sugar beet; by wind from the north-west, the fetch over the sugar beet is shortest, namely $20 \mathrm{~m}$. In all directions, the distance to the trees is more than $200 \mathrm{~m}$.

Two parts of the same fibre optic cable were suspended from this $6 \mathrm{~m}$ high mast. These parts of the cable were spiralled to obtain a vertical sampling resolution of $0.2 \mathrm{~m}$ of temperature observation along the axis of the spiral. One of the spirals was dry and the other was kept wet with a cotton cloth wrapped around the cable. Water was supplied continuously to the wet cable at two locations (at the top of the spiral and half way) (see Fig. 2). The water supply rate was not measured, but it is estimated to be roughly $100 \mathrm{Ld}^{-1}$. With an average latent heat flux of $100 \mathrm{~W} \mathrm{~m}^{-2}$ the supplied water is about $0.5 \%$ of the derived evaporation from an area of $80 \mathrm{~m} \times 80 \mathrm{~m}$. To diminish possible influences of the wet cable on the other measurements, the dry cable and the equipment of the reference techniques were installed upwind of the wet cable for the dominant wind direction.

From the $235 \mathrm{~m}$ fibre optic cable, the largest part ran over the ground to the setup in the middle of the field. At the setup, a distance of $15 \mathrm{~m}$ of cable was permanently placed in the calibration tank, ahead of the $30 \mathrm{~m}$ dry spiralled cable that ran from the bottom to the top of the mast. From the top, $30 \mathrm{~m}$ of wetted spiralled cable went down again. The last $15 \mathrm{~m}$ of the cable remained in the same calibration tank. To determine the exact position of the bottom of each spiralled cable, parts of the cable at the bottom were temporarily $(30 \mathrm{~min}$ at the beginning of the measurement campaign) immersed into an ice bath.

\subsubsection{Data processing}

The difference in air temperature $\left(\Delta T_{\mathrm{a}}\left({ }^{\circ} \mathrm{C}\right)\right)$, was derived from the temperature of the dry spiral. Although a white cable was used, the temperature of the dry spiralled cable might deviate from the actual air temperature due to exposure to direct sunlight. However, this is acceptable for determining Bowen ratio values as long as the gradients do not deviate from the real gradients (see Sect. 2.2.1).

The wet bulb temperature is derived from the temperature of the wetted cable. Not all measurement points on the wetted cable were used for data analysis. The reasons for excluding certain measurement points were if measurements were influenced by the supporting mechanism, if measurements were influenced by the (warmer) water supply or if measurements were located within the crop canopy instead of above the crop canopy. Figure 3 shows the points which were excluded from the data analysis and the specific reasons for exclusion.

The observed temperature profiles for the wetted cable in Fig. 3 clearly show the locations where water was released for permanent saturation of the cotton. Theoretically, the measurement points are located on a logarithmic profile. To determine which points should be excluded, a logarithmic profile (dotted line in Fig. 3) is fitted on two points on which the influence of the support or water supply system is assumed to be limited (red circles in Fig. 3). Fitting the logarithmic profile on two or multiple other points can lead to slight deviations in the profile; however, the number of excluded points is conservative, so it is not expected that fitting on other points would result in a difference in excluded points. In addition, this logarithmic profile is only used to exclude certain data points and not for determining temperature and vapour pressure gradients. 


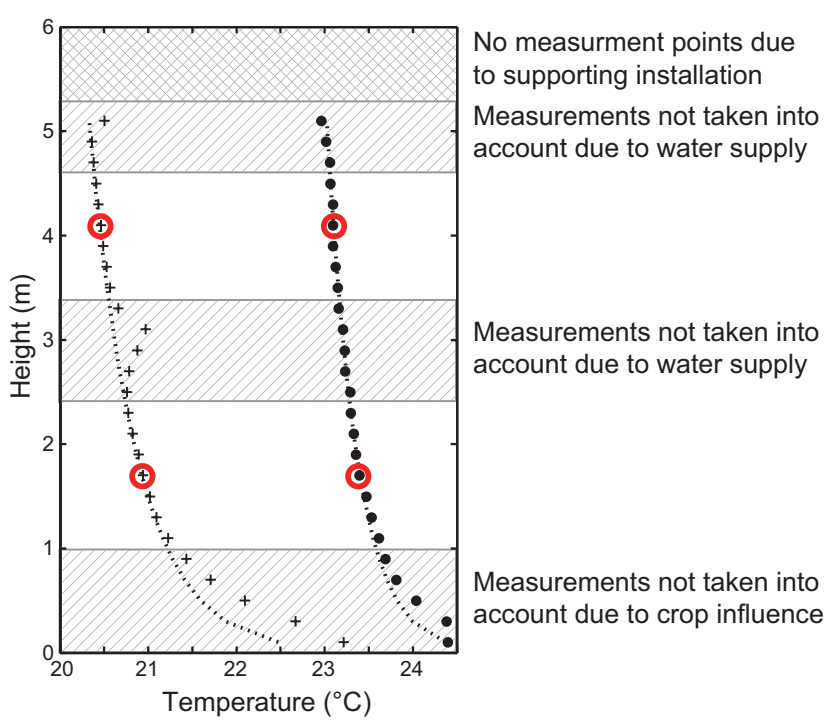

Figure 3. Temperature profiles measured with the dry and wet cable on 17 November 2011 at 12:00 h (for the period 11:45-12:15 LT). The grey bars indicate excluded data points ("+" for wet cable, “•”for dry cable). The dotted lines show a logarithmic profile, which is fitted to the data points indicated with a red circle.

The wet bulb temperature is used to determine the actual vapour pressure; the relation between these two variables is non-linear (Eq. 3). In theory, therefore, one needs the actual wet bulb temperatures, as a correct difference in wet bulb temperature is not sufficient to obtain the correct difference in actual vapour pressure as well. To obtain a correct wet bulb temperature, it is important that the amount of supplied water is not too much and not too little. Too little water causes the wet cable to dry, resulting in "wet bulb" temperatures that are too high. This was not the case during the experiment, as there was always some surplus water found along the cable. Too much water increases the adjustment length along the cable before the actual wet bulb temperature is reached. Therefore, 3-5 measurement points below each water supply location are excluded from the analysis (Fig. 3). From laboratory experiments under similar conditions, adjustment distances of $0.5-1.0 \mathrm{~m}$ were found. These distances were found by supplying water from the top to a hanging cotton-wrapped cable and measuring the distance beyond which the temperature did no longer decrease.

The Bowen ratio for BR-DTS and the corresponding correlation coefficient were determined through a linear regression between the measured dry cable temperature and the calculated actual vapour pressure, every $30 \mathrm{~min}$ for the same 7 and 13 data points (Fig. 4). Two sets with a different number of data points were used: one with 7 points (1.1$2.3 \mathrm{~m}$ ) and one with 13 points (1.1-2.3 and 3.3-4.5 $\mathrm{m}$ ). The reason is that the reference techniques were measuring between 1 and $2 \mathrm{~m}$ above the ground, meaning that the fetch for the reference techniques is more comparable with DTS

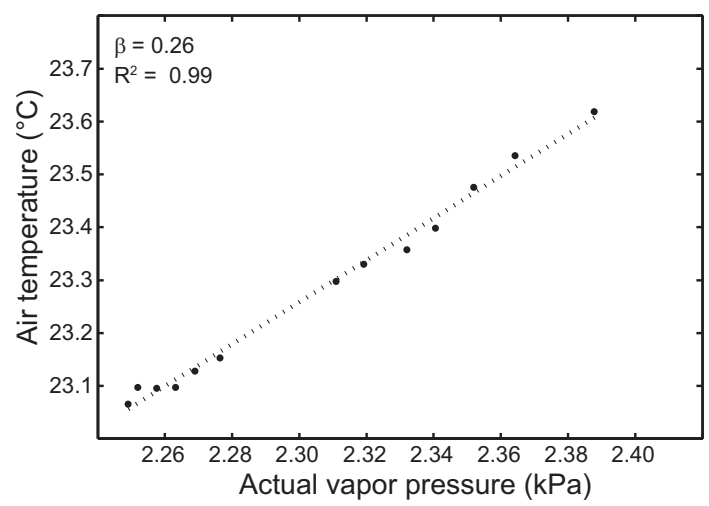

Figure 4. Example of calculation of a Bowen ratio: each dot represents a measurement in the vertical for 17 November 2011 at 12:00 h (for the period 11:45-12:15 LT); only the data points derived in Fig. 3 are used in this figure. The Bowen ratio was calculated by multiplying the slope of the trend line by the psychrometric constant, as described by Eq. (1).

measurements from 1.1-2.3 $\mathrm{m}$ than DTS measurements from $1.1-4.5 \mathrm{~m}$.

\subsection{Reference techniques}

The latent and sensible heat fluxes estimated from the BRDTS system were compared with the flux estimates from three conventional techniques. These techniques are eddy covariance (EC), surface layer scintillometer (SLS) and surface renewal (SR). The EC and SR setup were positioned within $15 \mathrm{~m}$ of the DTS tower, to ensure that all point measurement methods had the same upwind area. The eddy covariance measures both latent and sensible heat fluxes as point measurement. With the surface renewal technique sensible heat flux is derived as point measurement. The surface layer scintillometer measures the area-integrated sensible heat flux across a transect (e.g. Meijninger and de Bruin, 2000). As the frequency of measurement for all the aforementioned techniques was different, all data were converted to $30 \mathrm{~min}$ intervals for comparison.

\subsubsection{Eddy covariance (EC)}

A Campbell Scientific EC150 system was installed to obtain fluxes of water vapour and sensible heat flux above the sugar beet canopy. The system was mounted on a lattice mast at $2.0 \mathrm{~m}$ above the ground surface. The EC150 system consisted of a CR3000 data logger, a CSAT3 three-dimensional sonic anemometer (Campbell Scientific Inc., Logan, Utah, USA), an EC150 open path gas analyser and a HMP45C temperature and humidity probe. All necessary corrections were done for the EC data: correction of the sonic temperature for the effect of moisture, the Webb, Pearman and Leuning (WPL) correction to the water vapour flux for air density effects (Webb et al., 1980), and coordinate rotation. 


\subsubsection{Surface layer scintillometer (SLS)}

A dual-beam surface layer scintillometer (Scintec model SLS40-A) was used to measure the sensible heat flux density every $2 \mathrm{~min}$. The scintillometer's transmitter and receiver were positioned at a height of $1.5 \mathrm{~m}$ above the soil surface and the path length between the receiver and transmitter units was $90 \mathrm{~m}$. The SLS operates at a wavelength of $670 \mathrm{~nm}$. The SLS40-A employs a diode laser source with an output wavelength of $670 \mathrm{~nm}$ and $1 \mathrm{~mW}$ ( $2 \mathrm{~mW}$ peak) mean output power. The beam displacement and detector separation distances are $2.5 \mathrm{~mm}$ each with a detector diameter of $2.7 \mathrm{~mm}$. Measurements are obtained with a frequency of $1 \mathrm{kHz}$ and several subsequent micro-meteorological parameters are calculated, among others the sensible heat flux.

\subsubsection{Surface renewal (SR)}

For the surface renewal method, one unshielded type-E finewire thermocouple ( $75 \mu \mathrm{m}$ diameter) was used to measure air temperature fluctuations. It was placed at a height of $1.0 \mathrm{~m}$ above the soil surface. The thermocouple measurement was done differentially and air temperature data was sampled at a frequency of $10 \mathrm{~Hz}$. Time lags of 0.40 and $0.80 \mathrm{~s}$ were used for the surface renewal analysis before forming the second, third and fifth order of air temperature structure function values as required by the Atta (1977) approach. The calibration factor $\alpha$ was determined by plotting the SR sensible heat flux against eddy covariance EC estimates with a linear fit forced through the origin. The calibration factor $\alpha=1$ was obtained for the sugar beet canopy with the coefficient of determination of 0.90. Data were averaged every two minutes.

\subsection{Net radiation and soil heat flux}

The application of the BR-DTS method requires the measurement of net radiation and soil heat flux. Net radiation was measured at two locations approximately $10 \mathrm{~m}$ apart using a NR-LITE net radiometer (Kipp and Zonen, Delft, the Netherlands). Both were located at $1 \mathrm{~m}$ above the ground surface and situated within a $20 \mathrm{~m}$ radius of the BR-DTS experimental set up. For the data processing, the average of both sensors was used.

The soil heat flux was measured using two sets of soil heat flux plates (HFT-S, REBS, Seattle, WA) which were placed at a depth of $80 \mathrm{~mm}$ below the soil surface. One set was placed close to the BR-DTS setup in between two rows of crops and the other set was placed in the middle of the field between the sugar beet plants. Above the soil heat flux plates, soil temperature (using a system of parallel thermocouple soil-temperature-averaging probes at depths of 20 and $60 \mathrm{~mm}$ ) and soil moisture (using CS615 and CS616 time domain reflectometers) were measured. The records of soil moisture were used to determine the specific heat capacity of the soil which was central for heat storage calculations above the soil heat flux plates. The data from both measuring positions were processed and averaged for the energy balance calculations.

\subsection{Comparison of techniques}

The results of all techniques are compared based on $30 \mathrm{~min}$ averaged data. To compare all techniques, the slope and offset of the linear regression was used as a measure of bias, and the $R^{2}$ of the linear regression as a measure of variance. For the BR-DTS with 7 and with 13 data points, also the respective Bowen ratios are compared in time. In addition, the effect of wind direction on the BR-DTS results is investigated with a scatter plot. The advantage of using multiple data points compared to two data points is studied with scatter plots of the sensible heat fluxes as well.

A footprint analysis, based on the EC measurements, was undertaken to observe the relative contribution of upwind surface sources to the measured downwind sensible heat and latent energy fluxes, because the fetch over the sugar beet was limited. The footprint model developed by Hsieh et al. (2000), corrected and modified for a surface with a displacement height $d$ and surface roughness length $z_{0}$ (Savage et al., 2004), was used to estimate relative contributions from areas at various upwind distances $x$. The ratio between the measured flux $F$ and the surface source flux $S_{0}$ at a measurement height $z_{\mathrm{m}}$ was calculated using Eq. (10) for 3 days: 10 November (cloudy), 16 November (cloudless), and 17 November (partly cloudy) for unstable conditions during the peak hours of the measured fluxes (13:00 LT).

$\frac{F\left(x, z_{\mathrm{m}}-d\right)}{S_{0}}=\exp \left(\frac{-1}{\kappa^{2} x} D z_{u}^{P}\left|L_{0}\right|^{1-P}\right)$,

where $\kappa(=0.4)$ is von Karman's constant, $x$ the downwind fetch distance, $L_{0}$ the Obukhov length and $D$ and $P$ similarity constants, obtained by Hsieh et al. (2000) and expressed for different atmospheric stability conditions. The length scale $z_{u}$ expressed by Hsieh et al. (2000), and extended for a surface with a displacement height $d$ and surface roughness length $z_{0}$ (Savage et al., 2004), which is only valid for $z_{\mathrm{m}}>d+z_{0}$, is defined as

$z_{u}=\left(z_{\mathrm{m}}-d\right) \frac{z_{\mathrm{m}}-d}{z_{\mathrm{m}}-\left(d+z_{0}\right)}\left(\ln \frac{z_{\mathrm{m}}-d}{z_{0}}-1+\frac{z_{0}}{z_{\mathrm{m}}-d}\right)$.

\section{Results and discussion}

\subsection{Meteorological conditions}

In the 5-day measurement period, different meteorological conditions occurred. There were cloudless sunny days (9 and 16 November), a full day with overcast conditions (10 November) and partly cloudy days (17 and 18 November). Net radiation around noon varied between 100 and $700 \mathrm{~W} \mathrm{~m}^{-2}$. Wind direction varied during all days, but was 


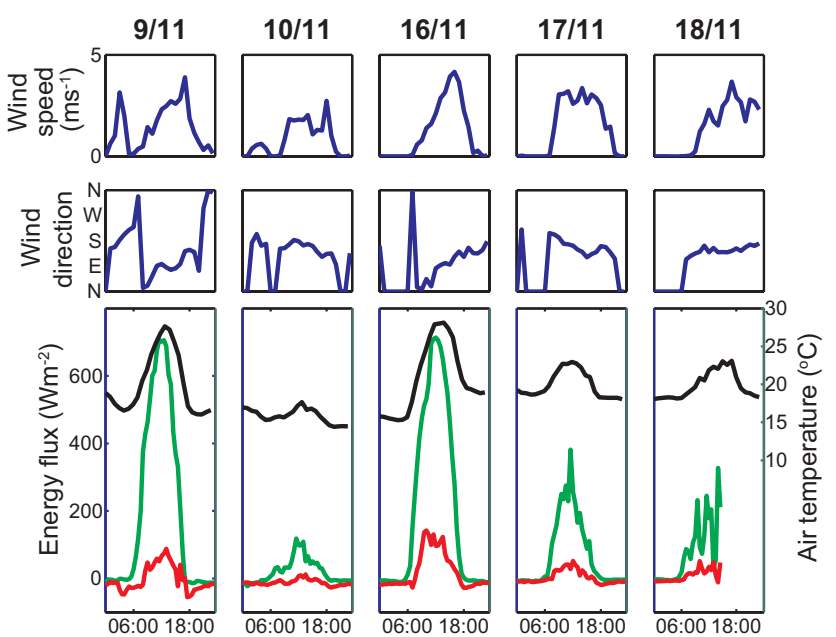

Figure 5. Meteorological conditions and energy fluxes for the days used in the data analysis. Top panel: wind speed. Middle panel: wind direction. Bottom panel: net radiation, soil heat flux and air temperature at $2 \mathrm{~m}$ height (green: net radiation, red: soil heat flux, black: temperature).

mainly between south and south-west. Wind speed varied between 0 and $4 \mathrm{~ms}^{-1}$ during the measurement period, with wind speed being the highest during the afternoon for most of the days. The lowest daytime averaged temperature was measured on 10 November and was $16^{\circ} \mathrm{C}$. The highest daytime averaged temperature was measured on 16 November and was $24^{\circ} \mathrm{C}$ (Fig. 5).

Figure 6 shows the results of the footprint analysis, which was performed for 10, 16 and 17 November. This was based on the ratio between the measured flux $F$ and surface source flux $S_{0}$ (Eq. 10). For all days, at least $75 \%$ of the measured flux is obtained from the area spanned by the shortest fetch $(20 \mathrm{~m})$ over the sugar beet field and at least $93 \%$ is obtained from the area spanned by the longest fetch $(80 \mathrm{~m})$ over the sugar beet field. Although the fetch over the sugar beet field is not constant in time, it is approximately equal for each technique, as they are located in close proximity.

\subsection{Performance of BR-DTS}

Figure 7 shows the calculated Bowen ratio values for the experimental days, together with the correlation coefficients $\left(R^{2}\right)$ at each $30 \mathrm{~min}$ interval derived from determining the Bowen ratio value based on the 7 and 13 measurement points (as explained in Sect. 2.2.3). High $R^{2}$ values indicate a linear relation for temperature and vapour pressure over the air column. The $R^{2}$ values were mostly high during the day with occasional low values. Differences between Bowen ratio values and $R^{2}$ values for the 7 and 13 points are probably caused by a longer fetch for the case with 13 points.

Both the sensible and latent heat flux were estimated from BR-DTS, using net radiation and ground heat flux. For the EC setup both terms are measured directly. However, from
Table 1. Daily average contribution of different fluxes to the energy balance.

\begin{tabular}{lrr}
\hline & $R_{\mathrm{n}}-G\left(\mathrm{~W} \mathrm{~m}^{-2}\right)$ & $H+\rho \lambda E\left(\mathrm{~W} \mathrm{~m}^{-2}\right)$ \\
\hline $9 \mathrm{Nov}$ & No EC data & No EC data \\
$10 \mathrm{Nov}$ & 19.1 & 41.5 \\
$16 \mathrm{Nov}$ & 170.0 & 139.3 \\
$17 \mathrm{Nov}$ & 59.3 & 26.5 \\
$18 \mathrm{Nov}$ & 56.0 & 46.6 \\
\hline
\end{tabular}

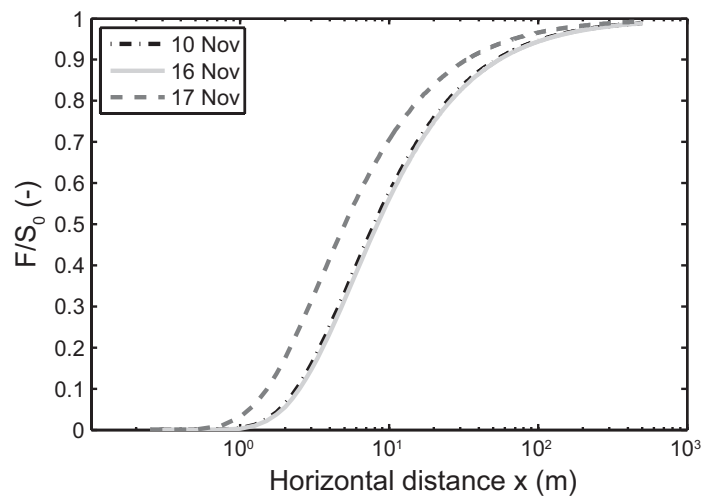

Figure 6. The ratio between $F$ and $S_{0}$ against horizontal distance from measurement setup.

the SLS and SR only the sensible heat flux can be derived without measurements of net radiation and ground heat flux. Therefore, in Fig. 8 the latent heat flux from BR-DTS is compared with the latent heat flux from EC (left panel) and the sensible heat flux from BR-DTS is compared with the sensible heat flux from all reference techniques (right panel).

As shown in Fig. 8 the latent heat flux estimates derived using the direct EC method were lower than those derived with the BR-DTS method. To investigate the difference between the two techniques an energy balance closure analysis was performed for the EC measurements. The daily average contributions of the different fluxes to the energy balance are presented in Table 1; at none of the measurement days was the energy balance closed. A lack of energy balance closures from EC measurements have been reported in the literature, which can be due to several reasons: erroneous measurements of the turbulent fluxes or the ground energy storage, or the occurrence of advection or heterogeneity of the field (Foken, 2008). Several studies of the energy balance terms failed to achieve closure, and the lack of energy balance closure has been found over all types of surfaces from bare soil to forests (Oncley et al., 2007). Therefore, the measured fluxes should be corrected or adjusted or the uncertainties in the measured fluxes should be accepted (Twine et al., 2000).

As the energy balance did not close, the values for the obtained latent heat flux are likely to be uncertain, which is a reason not to compare the latent heat flux of EC with 

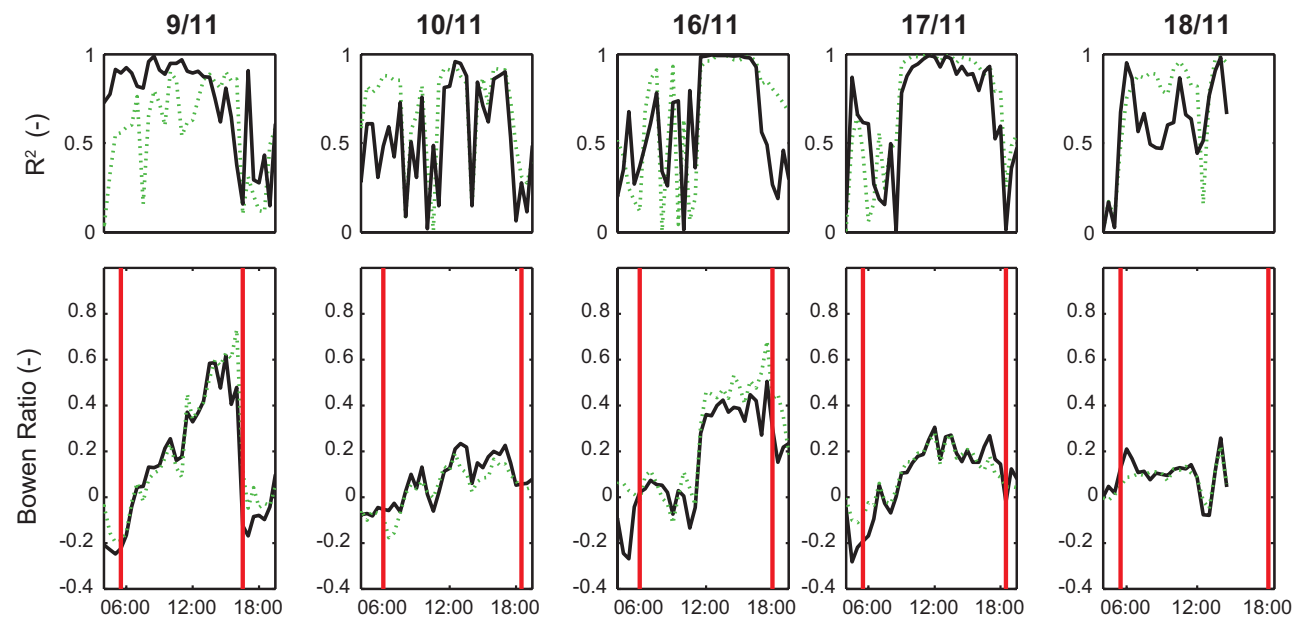

Figure 7. Top panel: $R^{2}$ value of linear regression between $T_{\mathrm{a}}$ and $e_{\mathrm{a}}$ for $7(1.1-2.3 \mathrm{~m})$ and 13 data points $(1.1-4.5 \mathrm{~m})$. Bottom panel: half hourly Bowen ratio values derived from the linear regression. Between the vertical red lines $R_{\mathrm{n}}$ is positive (solid black line for 7 points, dotted green line for 13 points).
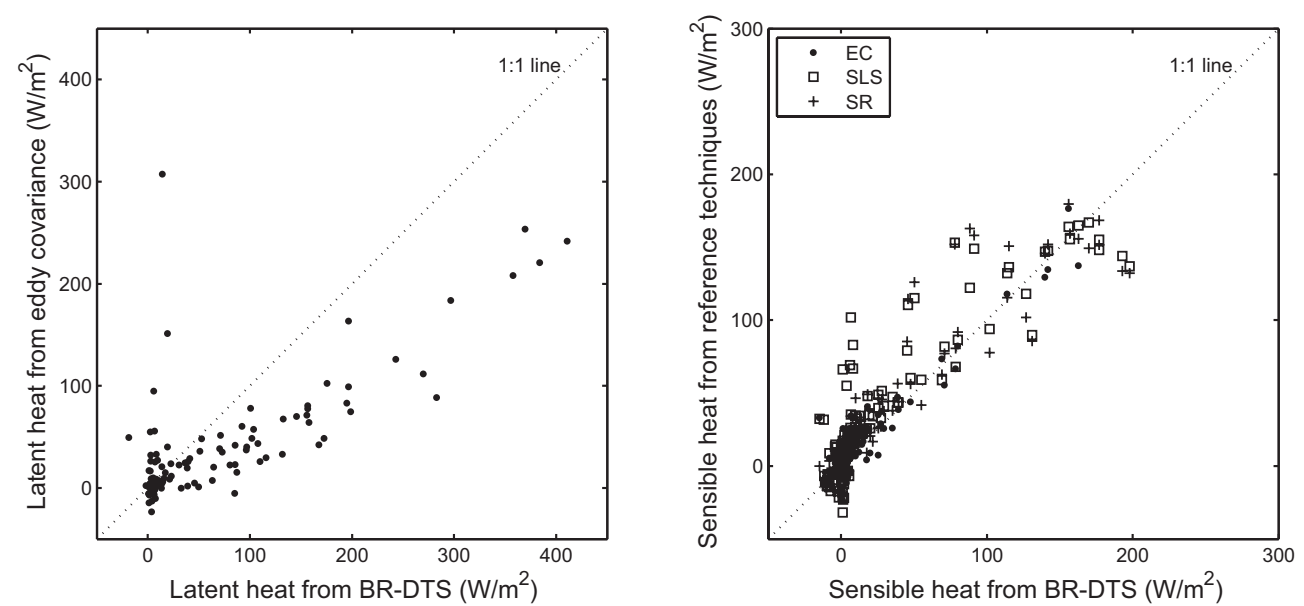

Figure 8. Results for BR-DTS compared with reference techniques. Left panel: latent heat flux from EC and BR-DTS (measurements from 1.1 to $2.3 \mathrm{~m}$ ). Right panel: sensible heat flux from EC, SLS, SR and BR-DTS (measurements from 1.1 to $2.3 \mathrm{~m}$ ). Measurements are shown for the days presented in Fig. 5, except for moments with north-eastern winds.

that of BR-DTS. For the sensible heat flux, three different techniques were used, which show similar results (Fig. 8, Table 2). Therefore, the assessment of the BR-DTS method was based on a comparison with the sensible heat fluxes from EC, SLS and SR.

The right-hand side panel in Fig. 8 shows a scatter plot for BR-DTS (7 points) against the reference techniques for the sensible heat flux. It can be seen that the difference for larger sensible heat values is smallest for the EC. BR-DTS shows an underestimation with respect to SR and SLS until sensible heat fluxes of approximately $150 \mathrm{~W} \mathrm{~m}^{-2}$ and for fluxes larger than $150 \mathrm{~W} \mathrm{~m}^{-2}$ an overestimation.

An overall over- or underestimation is further investigated by calculating a linear regression; the results are shown in Table 2. The presented slope and zero offset, can be regarded as a measure of bias between the methods. For EC, the zero offset is smallest, the slope is among the highest and the $R^{2}$ is the highest. For SLS and SR the offset is larger than for EC, which indicates in particular an underestimation by BR-DTS for the smaller values measured. Further, Table 2 shows that the linear regression between BR-DTS and the reference techniques is comparable with the linear regression among the reference techniques.

The slope of the linear regression between sensible heat flux of BR-DTS and the average of all other techniques (EC, SLS, SR) is 0.93 for 7 data points and 0.87 for 13 data points. The better agreement with 7 data points was expected, as the reference techniques also measure in the same region above the ground $(1-2 \mathrm{~m})$. The 13 data points include the 7 points, but measure over a longer fetch and, therefore the results deviate more from the reference techniques. 
Table 2. Linear regression results between sensible heat flux of all different methods. The first number shows the slope, the number below, in italics, is the zero offset $\left(\mathrm{W} \mathrm{m}^{-2}\right.$ ) and the number in square brackets shows the $R^{2}$ value. The linear regression is determined with a free offset and the methods in the first column were located on the $x$ axis. The linear regression is based on data from the days presented in Fig. 5 , with exclusion of moments with north-eastern winds.

\begin{tabular}{|c|c|c|c|c|c|c|}
\hline & BR-DTS (7 pts) & BR-DTS (13 pts) & EC & SLS & SR & average EC, SLS, SR \\
\hline & $1 ;[1]$ & $1.03 ;[0.97]$ & $0.94 ;[0.91]$ & $0.92 ;[0.81]$ & $0.95 ;[0.86]$ & $0.93 ;[0.88]$ \\
\hline BR-DTS (7 pts) & 0 & -0.2 & 2.6 & 7.9 & 4.5 & 4.7 \\
\hline DP DTC $(12 n t)$ & & $1 ;[1]$ & $0.85 ;[0.92]$ & $0.86 ;[0.77]$ & $0.87 ;[0.80]$ & $0.87 ;[0.82]$ \\
\hline BR-DIS (13 pts) & & 0 & 3.0 & 8.9 & 5.5 & 5.6 \\
\hline $\mathrm{EC}$ & & & $1 ;[1]$ & $0.99 ;[0.75]$ & $1.04 ;[0.95]$ & $\mathrm{n} / \mathrm{a}$ \\
\hline SLS & & & & $\begin{array}{l}1[1] \\
0\end{array}$ & $\begin{array}{l}0.93 ;[0.86] \\
0.1\end{array}$ & $\mathrm{n} / \mathrm{a}$ \\
\hline SR & & & & & $\begin{array}{l}1[1] \\
0\end{array}$ & $\mathrm{n} / \mathrm{a}$ \\
\hline
\end{tabular}

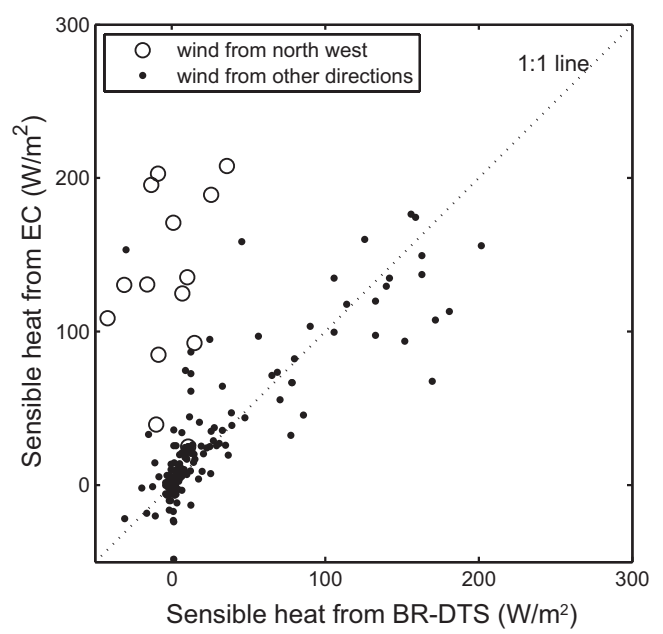

Figure 9. Comparison of the sensible heat flux of BR-DTS with sensible heat flux estimates from the eddy covariance from 9 to 18 November. Only the lower points of the DTS are used. Northeastern winds are winds from 345 to $50^{\circ}$.

For the comparison with the reference techniques only the sensible heat flux is used, while the latent heat flux is mainly interesting for evaporation research. The latent heat flux from BR-DTS, however, can be determined with the calculated Bowen ratio and the already derived sensible heat flux (Eq. 1). Therefore, a reliable estimate for the sensible heat flux, will likely lead to a reliable estimate for the latent heat flux as well.

Figure 8 only shows the data for periods without wind interferences. Data was excluded for cases where the wind is coming from north-eastern direction $\left(u>0.75 \mathrm{~ms}^{-1}\right.$ and from 345 to $50^{\circ}$ ). Under these conditions, the dry cable was located downwind from the wet cable and therefore, was wetted as well. Figure 9 shows that for the total measuring period the most outliers are indeed caused by these wind conditions.

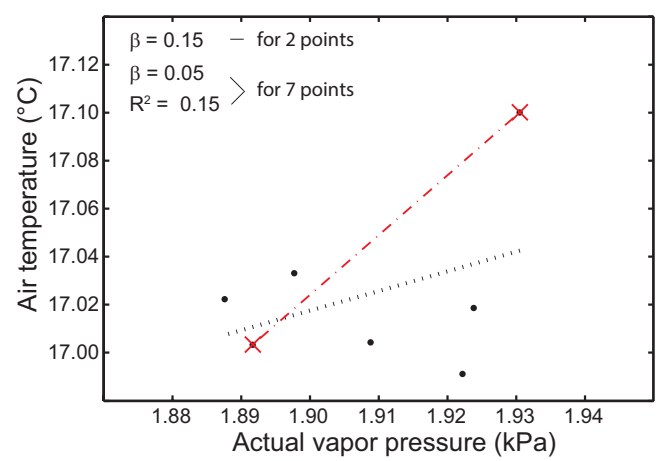

Figure 10. Derivation of Bowen ratio values based on two and seven data points in the vertical, 10 November, 14:00 LT (red crosses show the temperature and vapour pressure at 1.1 and $2.1 \mathrm{~m}$ ).

\subsection{Comparison of Bowen ratio for two versus multiple data points}

To assess the benefits of using BR-DTS above the conventional BR method, where the BR method is calculated based on only two points, a comparison was made between measuring at two levels and measuring at multiple (7 or 13) levels. The measurements at the two and multiple levels are derived from one sensor, the fibre optic cable. It should be realised that in the conventional BR setup independent sensors are used, which can introduce additional errors. This comparison consists of two parts: first the difference in the determined Bowen ratio and second the difference in the derived sensible heat flux.

A disadvantage of only using two measurement points is that it is not possible to assess how reliable the Bowen ratio values are. In contrast, this is possible by using multiple measurement points in a vertical. In Fig. 10 an example is provided of the derivation of a Bowen ratio value based on seven points and a Bowen ratio value based on measurement results at $1.1 \mathrm{~m}$ and $2.1 \mathrm{~m}$ heights. It can be seen that 

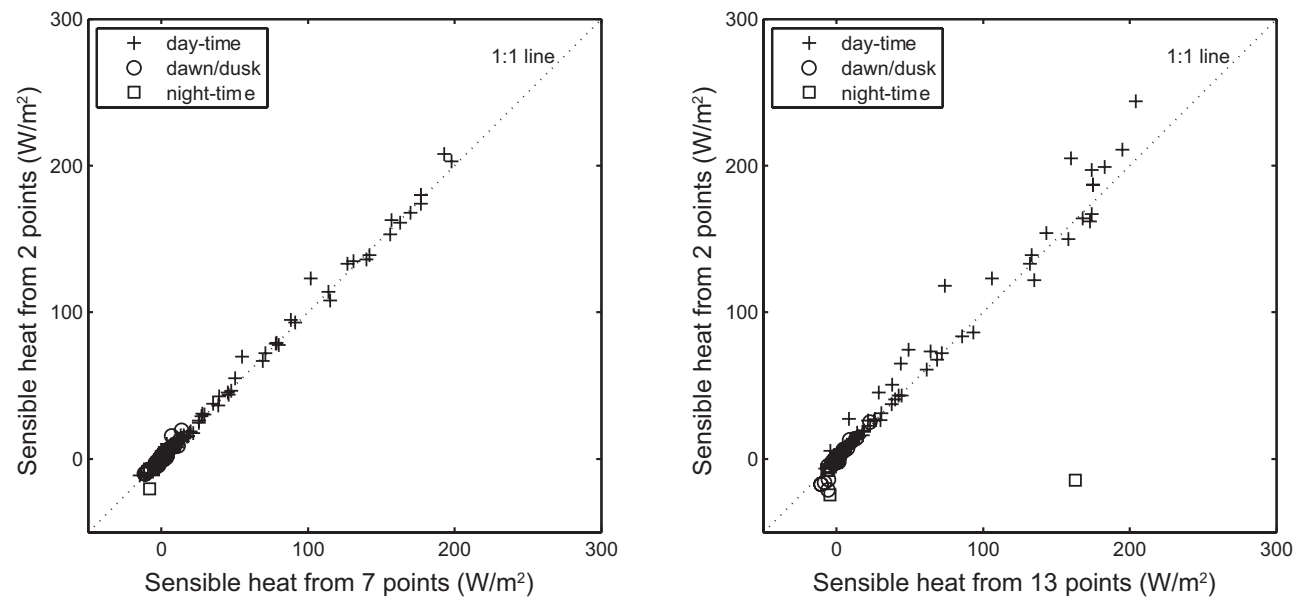

Figure 11. Sensible heat flux for the BR method with two points and with multiple points. Left panel: 2 points (1.1 and $2.1 \mathrm{~m})$ compared with 7 points $(1.1-2.3 \mathrm{~m})$. Right panel: 2 points (1.1 and 4.3 m) compared with 13 points (1.1-2.3 and 3.5-4.5 m) (daytime 07:00-17:00 LT, dawn 04:00-07:00 LT, dusk 17:00-20:00 LT, night-time 20:00-04:00 LT).

the Bowen ratio for two points is three times higher than for seven points. It is only possible to determine specific outliers when using multiple points. Therefore, multiple measurements give more insight into the measured profiles and lead to more verifiable results. It should be noted that the example provided has a low $R^{2}$ value for the regression between $T_{\mathrm{a}}$ and $e_{\mathrm{a}}$, while this is not the case for most of the measurements. However, this example is especially selected because with a low $R^{2}$ value the availability of multiple points is very important.

Although Bowen ratio values can be obtained with more confidence by using multiple measurement points, the effect of the improvement does not fully propagate into the derived latent and sensible heat fluxes. Equations (7) and (9) show that the relative error in latent and sensible heat flux comprise a term $\sigma_{\beta}^{2} /(1+\beta)^{2}$. As a consequence, with $\beta$ in the range from -0.3 to 0.7 for this study, the contribution of a relative error of $\beta$ into the relative error for the latent and sensible heat fluxes is reduced. This explains that the sensible heat fluxes derived from 2 data points and those derived from 7 or 13 data points do not deviate largely (Fig. 11).

\subsection{Advantages and disadvantages of BR-DTS}

DTS provides an option for high-spatial-resolution temperature profiles; to determine these profiles with multiple individual sensors, numerous accurate sensors and extensive calibration efforts are required. The DTS requires proper calibration as well, but the literature shows significant progress in standardising calibration procedures (e.g. Hausner et al., 2011; van de Giesen et al., 2012).

By using multiple measurements, more information is obtained about temperature and vapour pressure profiles over the air column, which gives more insight into the processes in the air column. For example, it can help to determine whether the logarithmic profile is developed and thus how reliable the results are. Furthermore, the effect of measuring at different heights can be investigated and therefore the influence of different fetch lengths on the measurement results can be assessed. More information about the profiles can also be of particular use when the distribution of latent or sensible heat fluxes in the vertical is investigated, for example comparing evaporation under and above the canopy.

From an operational point of view a number of points should be noted. The wetness of the cotton-wrapped cable needs to be maintained in order to obtain the actual "wet bulb" temperature but at the same time not influence the measurements of the dry cable. During the measurements reported in this paper, higher wind speeds exacerbated the possible wetting of the dry cable. The water supplied to the wetted cable was from a high-pressure irrigation system making fine tuning of the flow rate difficult. A more accurate control of the required water flow rate would be beneficial in reducing the risk of wetting the dry cable. In addition, a larger distance between the dry and wet cables and keeping the dry cable upwind of the wetted cable would be practical solutions to this problem.

It should be realised that the setup as applied in this study needs daily attention, e.g. electricity and water supply, and is at this stage mainly suitable for research purposes.

\section{Conclusions and recommendations}

This paper investigates the usefulness of the BR-DTS method for estimating Bowen ratio values. This was achieved by (1) comparing the results of sensible heat flux from the BRDTS against a number of well-established reference techniques (eddy covariance, scintillometer and surface renewal) and (2) by discussing the benefits of multi-level Bowen ratio 
measurements offered by the BR-DTS technique over the typical two-level approach.

The first comparison showed especially a good correlation between the sensible heat flux of the BR-DTS for seven data points and sensible heat flux of the reference techniques (slope of 0.93 , zero offset of $4.7 \mathrm{~W} \mathrm{~m}^{-2}$ and $R^{2}$ of 0.88 ). The second comparison showed that the difference between two and multiple level measurements were mainly visible in the Bowen ratio values and not so much in the resulting latent and sensible heat fluxes. However, measuring at multiple levels gives more insight into the temperature and vapour pressure profiles in the air column. This can be useful to assess the quality of the measurements and to investigate changes in fluxes within the vertical.

The study showed that BR-DTS is a method that can be considered for measurements of actual evaporation. The method produces values comparable to those from other techniques, produces Bowen ratio values with more confidence, as they are based on multiple data points, and gives more insight into the temperature and vapour pressure profiles.

Acknowledgements. We would like to thank Stan Schymanski, an anonymous referee and the editor for their valuable comments, which helped us to improve the presentation and the discussion of our results.

Edited by: T. Blume

\section{References}

Allen, R. G., Pereira, L. S., Raes, D., and Smith, M.: Crop evapotranspiration - Guidelines for computing crop water requirements, vol. 56, FAO - Food and Agriculture Organization of the United Nations, Rome, 1998.

Angus, D. E. and Watts, P. J.: Evapotranspiration - How good is the Bowen ratio method?, Agr. Water Manage., 8, 133-150, 1984.

Aston, A. R.: The effect of vertical separation of psychrometers on the determination of Bowen ratios over a young eucalypt forest, Agr. Forest Meteorol., 35, 299-307, 1985.

Atta, C. W. V.: Effect of coherent structures on structure functions of temperature in the atmospheric boundary layer, Arch. Mech., 29, 161-171, 1977.

Bastiaanssen, W. G. M., Cheema, M. J. M., Immerzeel, W. W., Miltenburg, I. J., and Pelgrum, H.: Surface energy balance and actual evapotranspiration of the transboundary Indus Basin estimated from satellite measurements and the ETLook model, Water Resour. Res., 48, W11512, doi:10.1029/2011WR01048, 2012.

Black, T. A. and McNaughton, K. G.: Psychrometric apparatus for Bowen-Ratio determination over forests, Bound-Lay. Meteorol., 2, 246-254, 1971.

Blume, T., Krause, S., Meinikmann, K., and Lewandowski, J.: Upscaling lacustrine groundwater discharge rates by fiber-optic distributed temperature sensing, Water Resour. Res., 49, 79297944, doi:10.1002/2012WR013215, 2013.
Bowen, I. S.: The ratio of heat losses by conduction and by evaporation from any water surface, Phys. Rev., 27, 779-787, 1926.

Burt, C. M., Mutziger, A. J., Allen, R. G., and Howell, T. A.: Evaporation Research: Review and Interpretation, J. Irrig. Drain Eng., 131, 37-58, 2005.

Courault, D., Seguin, B., and Olioso, A.: Review on estimation of evapotranspiration from remote sensing data: From empirical to numerical modeling approaches, Irrig. Drain. Syst., 19, 223-249, doi:10.1007/s10795-005-5186-0, 2005.

Dugas, W. A., Fritschen, L. J., Gay, L. W., Held, A. A., Matthlas, A. D., Relcosky, D. C., Steduto, P., and Stelner, J. L.: Bowen ratio, eddy correlation, and portable chamber measurements of sensible and latent heat flux over irrigated spring wheat, Agr. Forest Meteorol., 56, 1-20, 1991.

Dyer, A. J. and Hicks, B. B.: Flux-gradient relationships in the constant flux layer, Q. J. Roy. Meteorol. Soc., 96, 715-721, doi:10.1002/qj.49709641012, 1970.

Foken, T.: The energy balance closure problem: an overview, Ecol. Soc. Am., 18, 1351-1367, 2008.

Fritschen, L. J.: Accuracy of evapotranspiration determinations by the Bowen ratio method, IAHS Bull., 10, 38-48, 1965.

Frtischen, L. J. and Gay, L. W.: Environmental Instrumentation, Springer-Verlag, New York, 1979.

Fritschen, L. J. and Qian, P.: Net radiation, sensible and latent heat flux densities on slopes computed by the energy balance method, Bound-Lay. Meteorol., 53, 163-171, 1990.

Fritschen, L. J. and Simpson, J. R.: Surface energy balance and radiation systems: general description and improvements, J. Appl. Meteorol., 28, 680-689, 1989.

Fuchs, M. and Tanner, C. B.: Error analysis of bowen ratios measured by differential psychrometry, Agr. Meteorol., 7, 329-334, 1970.

Gavilán, P. and Berengena, J.: Accuracy of the Bowen ratio-energy balance method for measuring latent heat flux in a semiarid advective environment, Irrig. Sci., 25, 127-140, 2007.

Gleick, P. H. (Ed.): Water in crisis: a guide to the of world's freshwater resources, Oxford University Press for Pacific Institute, New York, 1993.

Hausner, M. B., Suárez, F., Glander, K. E., van de Giesen, N., Selker, J. S., and Tyler, S. W.: Calibrating Single-Ended FiberOptic Raman Spectra Distributed Temperature Sensing Data, Sensors, 11, 10859-10879, 2011.

Hoes, O. A. C., Schilperoort, R. P. S., Luxemburg, W. M. J., Clemens, F. H. L. R., and van de Giesen, N. C.: Locating illicit connections in storm water sewers using fiber-optic distributed temperature sensing, Water Res., 43, 5187-5197, 2009.

Hsieh, C., Katul, G., and Chi, T.: An approximate analytical model for footprint estimation of scalar fluxes in thermally stratified atmospheric flows, Adv. Water Resour., 23, 765-772, 2000.

Jara, J., Stockle, C. O., and Kjelgaard, J.: Measurement of evapotranspiration and its components in a corn (Zea Mays L.) field, Agr. Forest Meteorol., 92, 131-145, 1998.

Kalma, J. D., McVicar, T. R., and McCabe, M. F.: Estimating Land Surface Evaporation: A Review of Methods Using Remotely Sensed Surface Temperature Data, Surv. Geophys., 29, 421-469, 2008. 
Krzeminska, D. M., Steele-Dunne, S. C., Bogaard, T. A., Rutten, M. M., Sailhac, P., and Geraud, Y.: High-resolution temperature observations to monitor soil thermal properties as a proxy for soil moisture condition in clay-shale landslide, Hydrol. Process., 26, 2143-2156, 2011.

Malek, E. and Bingham, G. E.: Comparison of the Bowen ratioenergy balance and the water balance methods for the measurement of evapotranspiration, J. Hydrol., 146, 209-220, 1993.

Mauder, M., Cuntz, M., Drüe, C., Graf, A., Rebmann, C., Schmid, H. P., Schmidt, M., and Steinbrecher, R.: A strategy for quality and uncertainty assessment of long-term eddy-covariance measurements, Agr. Forest Meteorol., 169, 122-135, 2013.

Meijninger, W. M. L. and de Bruin, H. A. R.: The sensible heat fluxes over irrigated areas in western Turkey determined with a large aperture scintillometer, J. Hydrol., 229, 42-49, 2000.

Oncley, S. P., Foken, T., Vogt, R., Kohsiek, W., deBruin, H. A. R., Bernhofer, C., Christen, A., van Gorsel, E., Grantz, D., Feigenwinter, C., Lehner, I., Liebethal, C., Liu, H., Mauder, M., Pitacco, A., Ribeiro, L., and Weidinger, T.: The energy balance experiment EBEX-2000, Part I: overview and energy balance, BoundLay. Meteorol., 123, 1-28, 2007.

Peacock, C. E. and Hess, T. M.: Estimating evapotranspiration from a reed bed using the Bowen ratio energy balance method, Hydrol. Process., 18, 247-260, 2004.

Perez, P. J., Castellvi, F., Ibañez, M., and Rosell, J. I.: Assessment of reliability of Bowen ratio method for partitioning fluxes, Agr. Forest Meteorol., 97, 141-150, 1999.

Perry, C. J.: Efficient irrigation; inefficient communication; flawed recommendations, Irrig. Drain., 56, 367-378, 2007.

Rana, G. and Katerjib, N.: Measurement and estimation of actual evapotranspiration in the field under Mediterranean climate: a review, Eur. J. Agron., 13, 125-153, 2000.

Savage, M. J., Everson, C. S., Odhiambo, G. O., Mengistu, M. G., and Jarmain, C.: Theory and practice of evapotranspiration measurement, with special focus on SLS as an operational tool for the estimation of spatially-averaged evaporation, vol. WRC Report No:1335/1/04, WRC - South African Water Research Commission, Pretoria, South Africa, 2004.

Savage, M. J., Everson, C. S., and Metelerkamp, B. R.: Bowen ratio evaporation measurement in a remote montane grassland: Data integrity and fluxes, J. Hydrol., 376, 249-260, 2009.

Schoups, G., van de Giesen, N. C., and Savenije, H. H. G.: Model complexity control for hydrologic prediction, Water Resour. Res., 44, W00B03, doi:10.1029/2008WR006836, 2008.

Selker, J. S., Thévenaz, L., Huwald, H., Mallet, A., Luxemburg, W., van de Giesen, N., Stejskal, M., Zeman, J., Westhoff, M., and Parlange, M. B.: Distributed fiber-optic temperature sensing for hydrologic systems, Water Resour. Res., 42, W12202, doi:10.1029/2006WR005326, 2006.

Sellers, P. J., Mintz, Y., Sud, Y. C., and Dalcher, A.: A Simple Biosphere Model (SIB) for Use within General Circulation Models, J. Atmos. Sci., 43, 505-531, 1986.

Sensornet: ORYX DTS - Data sheet, link not available anymore, 2009.
Spittlehouse, D. L. and Black, T. A.: Evaluation of the Bowen ratio/energy balance method for determining forest evapotranspiration, Atmos. Ocean, 18, 98-116, 1980.

Steele-Dunne, S. C., Rutten, M. M., Krzeminska, D. M., Hausner, M., Tyler, S. W., Selker, J., Bogaard, T. A., and van de Giesen, N. C.: Feasibility of soil moisture estimation using passive distributed temperature sensing, Water Resour. Res., 46, W03534, doi:10.1029/2009WR008272, 2010.

Teixeira, A. H. C. and Bastiaanssen, W. G. M.: Five methods to interpret field measurements of energy fluxes over a microsprinkler-irrigated mango orchard, Irrigation Sci., 30, 13-28, doi:10.1007/s00271-010-0256-y, 2011.

Teixeira, A. H. C., de Castro, A. H., Bastiaanssen, W. G. M., and Bassoi, L. H.: Crop water parameters of irrigated wine and table grapes to support water productivity analysis in the Sao Francisco river basin, Brazil, Agr. Water Manage., 94, 31-42, 2007.

Todd, R. W., Evett, S. R., and Howell, T. A.: The Bowen ratioenergy balance method for estimating latent heat flux of irrigated alfalfa evaluated in a semi-arid, advective environment, Agr. Forest Meteorol., 103, 335-348, 2000.

Twine, T. E., Kustas, W. P., Norman, J. M., Cook, D. R., Houser, P. R., Meyers, T. P., Prueger, J. H., Starks, P. J., and Wesely, M. L.: Correcting eddy-covariance flux underestimates over a grassland, Agr. Forest Meteorol., 103, 279-300, 2000.

Tyler, S. W., Selker, J. S., Hausner, M. B., Hatch, C. E., Torgersen, T., Thodal, C. E., and Schladow, S. G.: Environmental temperature sensing using Raman spectra DTS fiber-optic methods, Water Resour. Res., 45, W00D23, doi:10.1029/2008WR007052, 2009.

Uhlenbrook, S., Roser, S., and Tilch, N.: Hydrological process representation at the meso-scale: the potential of a distributed, conceptual catchment model, J. Hydrol., 291, 278-296, 2004.

van de Giesen, N., Steele-Dunne, S., Jansen, J., Hoes, O., Hausner, M., Tyler, S., and Selker, J.: Double-ended calibration of fiberoptic Raman spectra distributed temperature sensing data, Sensors, 12, 5471-5485, 2012.

Webb, E. K., Pearman, G. I., and Leuning, R.: Correction of flux measurements for density effects due to heat and water vapour transfer, Q. J. Roy. Meteorol. Soc., 106, 85-100, 1980.

Westhoff, M. C., Bogaard, T. A., and Savenije, H. H. G.: Quantifying the effect of in-stream rock clasts on the retardation of heat along a stream, Adv. Water Resour., 33, 1417-1425, 2010.

Wipfler, E. L., Metselaar, K., van Dam, J. C., Feddes, R. A., van Meijgaard, E., van Ulft, L. H., van den Hurk, B., Zwart, S. J., and Bastiaanssen, W. G. M.: Seasonal evaluation of the land surface scheme HTESSEL against remote sensing derived energy fluxes of the Transdanubian region in Hungary, Hydrol. Earth Syst. Sci., 15, 1257-1271, doi:10.5194/hess-15-1257-2011, 2011.

Xing, Z., Chow, L., Meng, F. R., Rees, H. W., Stevens, L., and Monteith, J.: Validating Evapotranspiraiton Equations Using Bowen Ratio in New Brunswick, Maritime, Canada, Sensors, 8, 412 428, 2008. 